\title{
LETTER
}

\section{Fluid resuscitation in septic shock: too much, too little or just right?}

\author{
John R Prowle* \\ See related research by Smith and Perner, http://ccforum.com/content/16/3/R76
}

In their interesting observational study Smith and Perner [1] describe fluid resuscitation (FR) in 164 patients with septic shock, concluding that survival was better in patients receiving higher volumes over the first $72 \mathrm{~h}$. I think we should be cautious, however, to conclude from this that more is better.

Median FR was $4.0 \mathrm{~L}$ over $24 \mathrm{~h}$, and $7.5 \mathrm{~L}$ by $72 \mathrm{~h}-$ relatively small volumes for patients with ongoing shock. FR volumes reported from trials performed in septic shock are substantially larger despite comparable illness severity; mean FR over $72 \mathrm{~h}$ was approximately $19 \mathrm{~L}$ in the Vasopressin in Septic Shock Trial (VASST) study [2], $13 \mathrm{~L}$ in the study by Rivers and colleagues [3] and $16 \mathrm{~L}$ in another recent study [4]. Indeed, median FR in the highvolume group (10.9 L at $72 \mathrm{~h}$ ) was comparable to the lowest quartile, associated with the best prognosis, in the VASST study (16 L at $96 \mathrm{~h}$ ) [2]. Thus, I do not believe that the benefit of higher-volume FR described is in conflict with the harm associated with larger volumes reported previously [2]. Similarly, median FR in the lower-volume group was only $4.3 \mathrm{~L}$ in $72 \mathrm{~h}$. As FR was physiciandirected, lower-volume FR might have been indicated by factors like chronic cardiac failure or fluid unresponsiveness associated with poorer outcomes irrespective of FR; no evidence is provided to conclude that increasing FR in this group would have improved survival.

Overall, this report records excellent outcomes using moderate FR by recent standards. Further trials are needed to characterize the dose and indications for FR in septic shock.

\section{Authors' response}

Anders Perner and Søren H Smith

Thanks to Dr Prowle for his interest in our study. We agree that observations in cohort studies should be interpreted with caution, in particular in complex clinical settings such as fluid resuscitation of patients with sepsis in the ICU. The interpretation of studies in this area is further complicated by differences in the reporting of fluid therapy. The types of, and indications for, fluids are most often not reported, so when previous trials [2-4] report that more than $10 \mathrm{~L}$ of fluid was given by day 3 , we do not know if this fluid was given for resuscitation. In trials of fluid resuscitation [5] (unpublished observations from the $6 \mathrm{~S}$ trial [6]), $2.5 \mathrm{~L}$ of other fluids were given for each liter of resuscitation fluid. The indications for giving other fluids may include nutrition, maintenance, fluids with medications and electrolytes or even to keep a drip

*Correspondence: john.prowle@bartshealth.nhs.uk

Adult Critical Care Unit, The Royal London Hospital, Barts Health, Whitechapel Road, London E1 1BB, UK open, but we do not know the details. Taken together, we support the notion that the controversy of fluid volume in septic shock may only be resolved in randomized trials of higher versus lower fluid volumes in these patients. Such trials should be top priority for the ICU research community.

\section{Abbreviations}

FR, fluid resuscitation; VASST, Vasopressin in Septic Shock Trial.

\section{Competing interests}

The author declares that he has no competing interests.

Published: 29 June 2012

\section{References}

1. Smith SH, Perner A: Higher vs. lower fluid volume for septic shock: clinical characteristics and outcome in unselected patients in a prospective, multicenter cohort. Crit Care 2012, 16:R76.

2. Boyd JH, Forbes J, Nakada TA, Walley KR, Russell JA: Fluid resuscitation in septic shock: a positive fluid balance and elevated central venous pressure are associated with increased mortality. Crit Care Med 2011, 39:259-265.

3. Rivers E, Nguyen B, Havstad S, Ressler J, Muzzin A, Knoblich B, Peterson E, Tomlanovich M: Early goal-directed therapy in the treatment of severe 
sepsis and septic shock. NEng/ J Med 2001, 345:1368-1377.

4. Jones AE, Shapiro NI, Trzeciak S, Arnold RC, Claremont HA, Kline JA,

Emergency Medicine Shock Research Network I: Lactate clearance vs central venous oxygen saturation as goals of early sepsis therapy: a randomized clinical trial. JAMA 2010, 303:739-746.

5. Finfer S, McEvoy S, Bellomo R, McArthur C, Myburgh J, Norton R: Impact of albumin compared to saline on organ function and mortality of patients with severe sepsis. Intensive Care Med 2011, 37:86-96.

6. Perner A, Haase N, Wetterslev J, Aneman A, Tenhunen J, Guttormsen AB, Klemenzson G, Pott F, Bodker KD, Badstolokken PM, Bendtsen A, Soe-Jensen P, Tousi H, Bestle M, Pawlowicz M, Winding R, Bulow HH, Kancir C, Steensen M, Nielsen J, Fogh B, Madsen KR, Larsen NH, Carlsson M, Wiis J, Petersen JA,
Iversen S, Schoidt O, Leivdal S, Berezowicz P, et al:: Comparing the effect of hydroxyethyl starch 130/0.4 with balanced crystalloid solution on

mortality and kidney failure in patients with severe sepsis (6S -

Scandinavian Starch for Severe Sepsis/Septic Shock trial): study protocol, design and rationale for a double-blinded, randomised clinical trial. Trials 2011, 12:24.

doi:10.1186/cc11362

Cite this article as: Prowle JR: Fluid resuscitation in septic shock: too much, too little or just right? Critical Care 2012, 16:436 